\title{
3rd Molar variations via radiograph
}

\author{
Ghazfa Jamil' ${ }^{1}$, Maha Syed ${ }^{1}$, Hasan Baber ${ }^{2 *}$, Zia Abbas ${ }^{2}$, Muzna Khalid ${ }^{2}$ and Summaiya Abdul Rehman ${ }^{2}$ \\ ${ }^{1}$ Private Dental Practitioner, Karachi \\ ${ }^{2}$ Dow University of Health Sciences, Karachi, Pakistan
}

\begin{abstract}
Objectives: To determine Morphological variations in Third Molars as seen on Panoramic Radiograph only, and determine a possible association of these variations with gender and different age groups divided into 5 groups from 18 years to 55 years, visiting Dental Department of Dow University of Health Sciences.

Methodology: Retrospective Observational study based on OPG of patients visiting department of oral medicine and radiology at DOW University of health sciences, Karachi were selected. For purpose of our study OPG of 350 patients were selected. After considering the inclusion and exclusion criteria 240 radiographs of patients aged 18 years and older were included in this study. Age study samples were categorized into 5 age groups. Chi Square test was used to predict possible associations between $3^{\text {rd }}$ molars variations in morphology and Gender/Age groups.
\end{abstract}

Results: Young Females had full bony mandibular impactions which was statistically significant $\mathrm{X}^{2}(1): 2.32, \mathrm{P}=0.00$. Increased variations in morphology such as multiple roots, long, fused and dilacerated roots were more prevalent in young individuals specially females.

Conclusion: Variation in $3^{\text {rd }}$ Molars are observed to vary among different age groups and Gender, further studies among different individuals from different ethnic backgrounds and culture will reveal new insights on these observed variations.

\section{Introduction}

Tooth impaction is a pathological condition in which a tooth fail to attain its normal functional position. Etiology of permanent tooth impaction includes several systemic and local factors. Cleidocranial dysplasia, Down syndrome, Endocrine deficiencies (hypothyroidism and hypopituitarism), Febrile diseases, and Irradiation are some of the systemic factors that may influence Impaction of permanent teeth. Most common local factors include prolonged deciduous tooth retention, Malposed tooth germs, Arch length deficiency, Supernumery teeth, odontogenic tumors abnormal eruption pathways and cleft lip and palate.

Intraoral techniques like periapical radiographs, extra oral techniques like lateral oblique, panoramic method, skull radiography and computed tomography are often used for dental imaging. Panoramic radiograph is suggested as the technique of choice to evaluate third molars.

Third molar is the most frequently impacted tooth and its prevalence ranges from $16.7 \%$ to $68.6 \%$ [1].

Objective of present study are to determine Morphological variations in Third Molars as seen on Panoramic Radiograph only, and determine a possible association of these variations with gender and different age groups.

This could help in early diagnosis in different types of impactions, which could further aid in early intervention in order to save the adjacent dentition.

Two hypothesis were designed to find an association in Morphology/ Position of $3^{\text {rd }}$ Molars with respect to Gender and Different age groups. These are as follows:

1. Morphological variations in $3^{\text {rd }}$ Molars are often observed in Females
2. Young individuals have normal multiple $3^{\text {rd }}$ molar roots than older individuals.

\section{Methodology}

Retrospective Observational study based on OPG of patients visiting department of oral medicine and radiology at DOW University of health sciences, Karachi were selected. For purpose of our study OPG of 350 patients were selected using convenient sampling, from the available OPG images in the hospital records. After considering the inclusion and exclusion criteria 240 radiographs of patients aged 18 years and older (112males and 128 females) were included in this study. Age study samples were categorized into 5 age groups.

The inclusion criteria for selection of radiographs were that the OPG must be clear and decipherable, presence of fully or partially erupted $3^{\text {rd }}$ molar as seen in OPG and Age of patient should be 18 years and above. Intra Examiner reliability was not evaluated.

The exclusion criteria of study are edentulous patients, patient age less than 19 years, mandibular fractures, and orthodontic treatment cases, congenitally missing all four $3^{\text {rd }}$ molars, presence of incomplete records or poor quality OPG.

Demographic data including age and gender was extracted from DOW university hospital record. The radiographs were taken according to the panoramic machine (Rotograph eve ${ }^{\mathrm{mi}}$ specifications which

Correspondence to: Hasan Baber BDS,Msc(UK),Pg Dip(UK),MBA(UK), Assistant Professor, Dow University of Health Sciences, Karachi, Pakistan, E-mail: relicpassion@yahoo.com

Key words: 3 rd molars, OPG, ankylosis, roots, morphology, variations Received: June 05, 2017; Accepted: June 15, 2017; Published: June 19, 2017 
has a constant magnification of 2.0. For radiographic examination 15 relevant questions were formulated. Each radiograph was viewed digitally in a dark room and measurements were made using a digital software called DICOM viewer and Analyzer.

Third molar was considered impacted if it was not in functional occlusion and at the same time, its roots were fully formed [2]. Soft tissue impaction was considered, when the height of the tooth's contour was above the level of the surrounding alveolar bone and the superficial portion of the tooth was covered only by soft tissue. Hard Tissue ('Bony') Impaction where the $3^{\text {rd }}$ molar fails to erupt due to being obstructed by the overlying bone. Angulations of impacted $3^{\text {rd }}$ molars were recorded based on winter's classification. The distance in millimeters between the inferior most part of the tooth and the superior border of the inferior alveolar canal was measured using a digital distance measuring tool on software called DICOM viewer and Analyzer (micro dicom)". Outline of the inferior alveolar canal was traced to record its relation to the third molar root apices [3].

\section{Data interpretation}

Data was analyzed using a Pearson chi-square $(\chi 2)$ test, performed using the Statistical Package for the Social Sciences (version 22.0; SPSS Inc., Chicago, IL).

\section{Results}

There was statistically significant association between type of mandibular impactions and Gender, $\mathrm{X}^{2}(1)=5.32, \mathrm{P}=0.004$. Radiographs revealed females having more bony impactions than males.

Number of roots and gender was also associated statistically significant $\mathrm{X}^{2}(1)=8.76, \mathrm{P}=0.03$. Radiograph demonstrated females having more single rooted molars than males.

Position of Mandibular $3^{\text {rd }}$ Molar crowns was strongly associated with age of patient. $\mathrm{X}^{2}(1)=30.172, \mathrm{P}=0.017$. Younger individuals had more vertical impactions than older individuals.

Normal Morphology of Man $3^{\text {rd }}$ Molar roots was strongly associated with age $\mathrm{X}^{2}(1)=37.10, \mathrm{P}=0.01$

We have been able to accept our hypothesis as we observe morphological variations in 3rd Molars are often observed in Females and young individuals have normal multiple $3^{\text {rd }}$ molar roots than older individuals.

Further findings are tabulated in results below: (Graphs 1-5)

\section{Discussion}

Impaction are a usual finding in patients coming in dental OPD or private clinics. Majority of dentist recommend extraction of impaction on the account if there is infection or pain present, resorption of adjacent tooth is taking place or a cyst is forming on a radiograph [4].

Third Molars are the last teeth to erupt in all races irrespective of racial differences in the eruption sequence. This late eruption is one of the major etiological factor this tooth is most commonly impacted. Jaw size, facial growth and size of the tooth varies among different cultures and population groups and have marked inheritance pattern. These factors are also essential for eruption pattern, status of impaction and agenesis seen in third molars [5]

The mean age group of our study group was 33.2 years $( \pm 11.776 \mathrm{std}$ deviation).Quek and Schersten et al. [6] have shown mean age of their subjects as $19.3,26.5 \pm 5$ and 20 to 25 years respectively. The proportion of patients having all four third molars was more than half (64\%), which is lower than in study done by Sandu [7] (76\%) in Indian Population and Hattab [8] (73\%) in Jordanian population. Possible reason for lower number might be due to the fact as it is observed in Pakistan extraction of molars upon caries or other pathology is common due to high cost of RCT and Restoration compared with simple extraction.

$73 \%$ had third molar impactions, with $30 \%$ in maxilla while mandible accounted for $70 \%$ of all impactions. The results are in line with Amr M Bayoumi et al. [9] who reported 580 OPG with mandibular impactions (52.8\%) being more than maxillary impaction (47.4\%).

Unilateral impaction was commonly observed in Maxilla while bilateral was more common in Mandible. A study in Nigeria by Olasoji [10] reported prevalence rate of third molar impactions in countries with high standard of living ranges from 9.5 to $25 \%$. The prevalence rate in study done by Haider et al. [11] is close to what was reported in study examining 1000 OPG in Singapore Chinese Population (68.6\%) and (65.6\%) other on American population reporting 500.

The increased prevalence observed in our study can be attributed due to the fact that Karachi is a metropolitan city and people of multiple ethnic backgrounds report daily in Dental OPDs thus increased variations and number of impactions observed [12].

Although there was no major difference in number of impaction among males and females, but females had slightly higher predilection than males. Contrary to our study no gender predilection was observed in study by Secic et al. [13]. This slight difference can be accounted due to female radiographs being little more than male radiograph.

The fact that different authors use different methodologies to classify angulations, it is hard to compare angulations among different studies. Vertical angulation is found to be highest (61\%) in Males and (56\%) in Females in Maxilla. Although it does not coincide with that of Hashemipour et al. [14] whose finding concluded Mesioangular impactions in third molar to be the most frequent.

Vertical Impaction was also found to be highest in Mandible (42\% Males \& 45\% Females). This is in line with Anwar Bataineh et al. [15], who also reported vertical Impaction in Mandible to be highest amongst others. Amr M Bayoumi et al. [16] reported Mesioangular impaction to be most common in their findings. Differences between these findings can be accounted as a result of different methods used for classifying angulations.

Present study had single root most common in Maxilla and two roots common in Mandible. Majority of the clinicians have considered two roots as being the normal anatomy of third molars. Sidow et al. [17] in his study on 150 samples of third molars reported $17 \%$ one, $77 \%$ two and $5 \%$ and $1 \%$ three and four roots respectively. Although his study demonstrated two root types third molars to be the common once in mandibular molars. Unlike our findings of single root in maxillary third molar, he reported three root type (45\%) as the most common number of roots in Maxilla. Shishir Singh et al. [18] studied 100 Maxillary molars among South Asian Population and found one root third molars to be the least amongst other types. G. Townsead et al. [19] suggested that certain traits such as the 'three-rooted molar' had a high degree of genetic penetrance. These differences in Maxillary third molars can be accounted due to cultural diversity in our radiographs. 


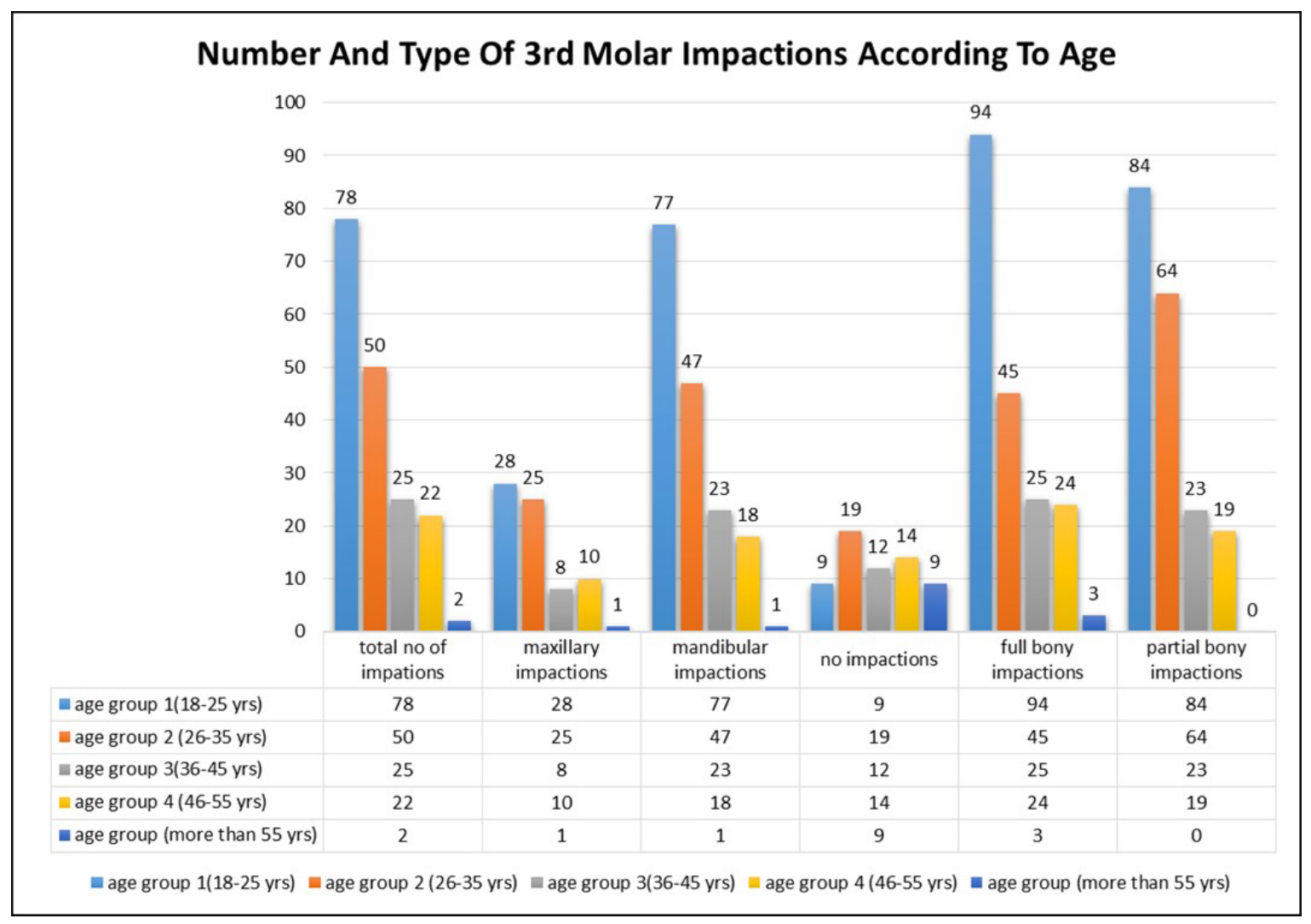

Graph 1. Number and Type of $3^{\text {rd }}$ Molar Impactions According to Age

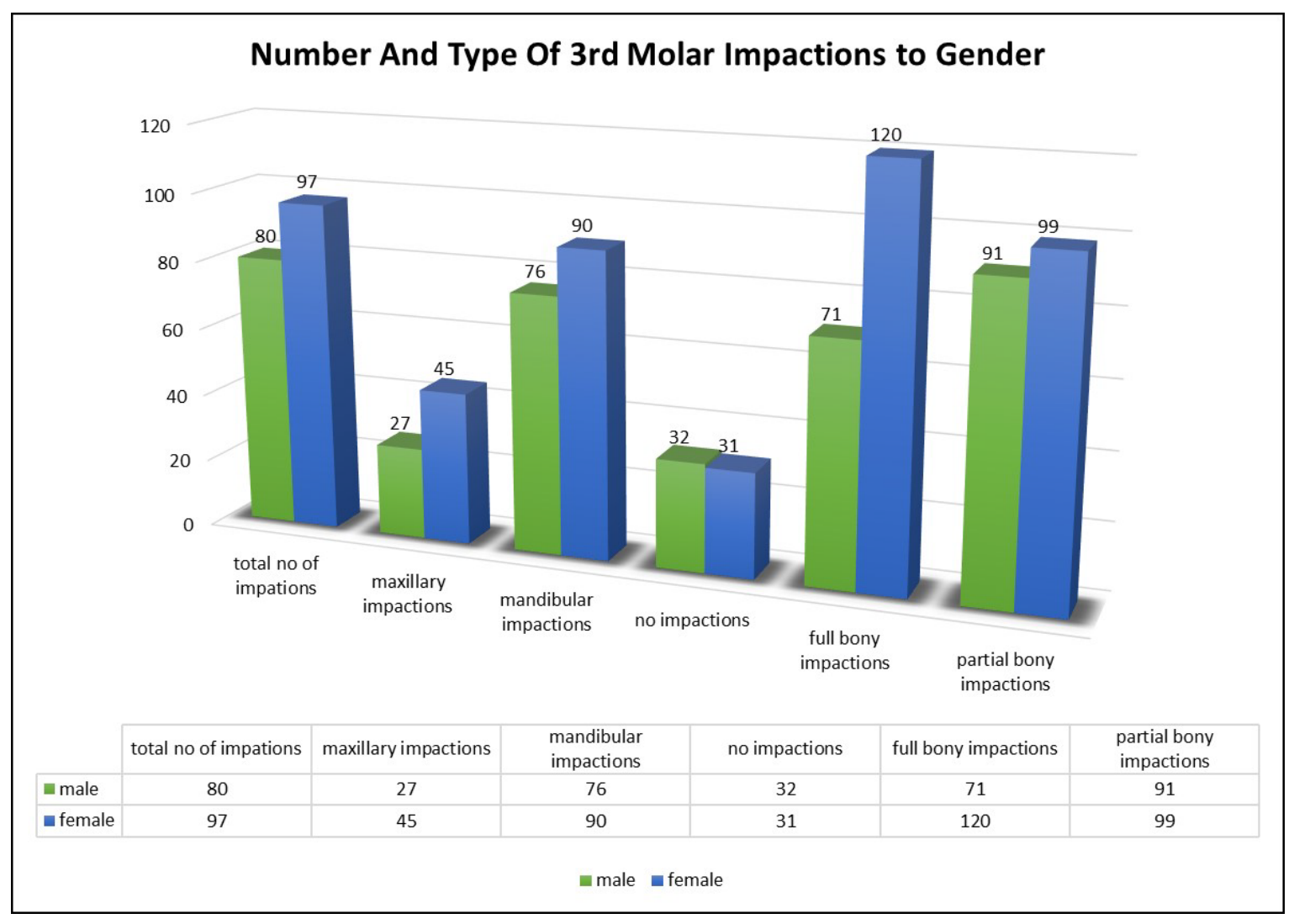

Graph 2. Number and Type of $3^{\text {rd }}$ Molar Impactions According to Gender 


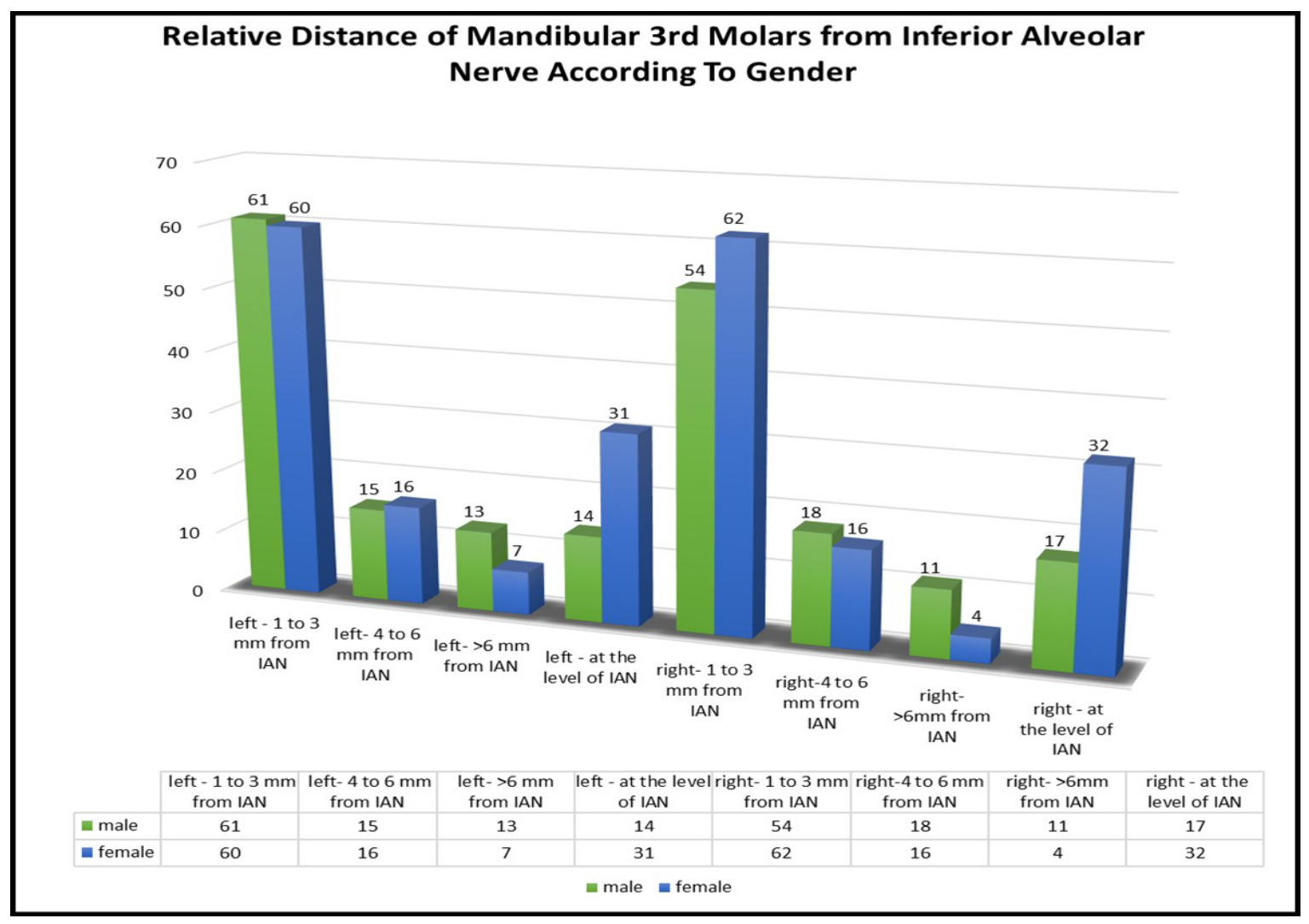

Graph 3. Relative Distance of Mandibular $3^{\text {rd }}$ Molars from Inferior Alveolar Nerve According to Gender

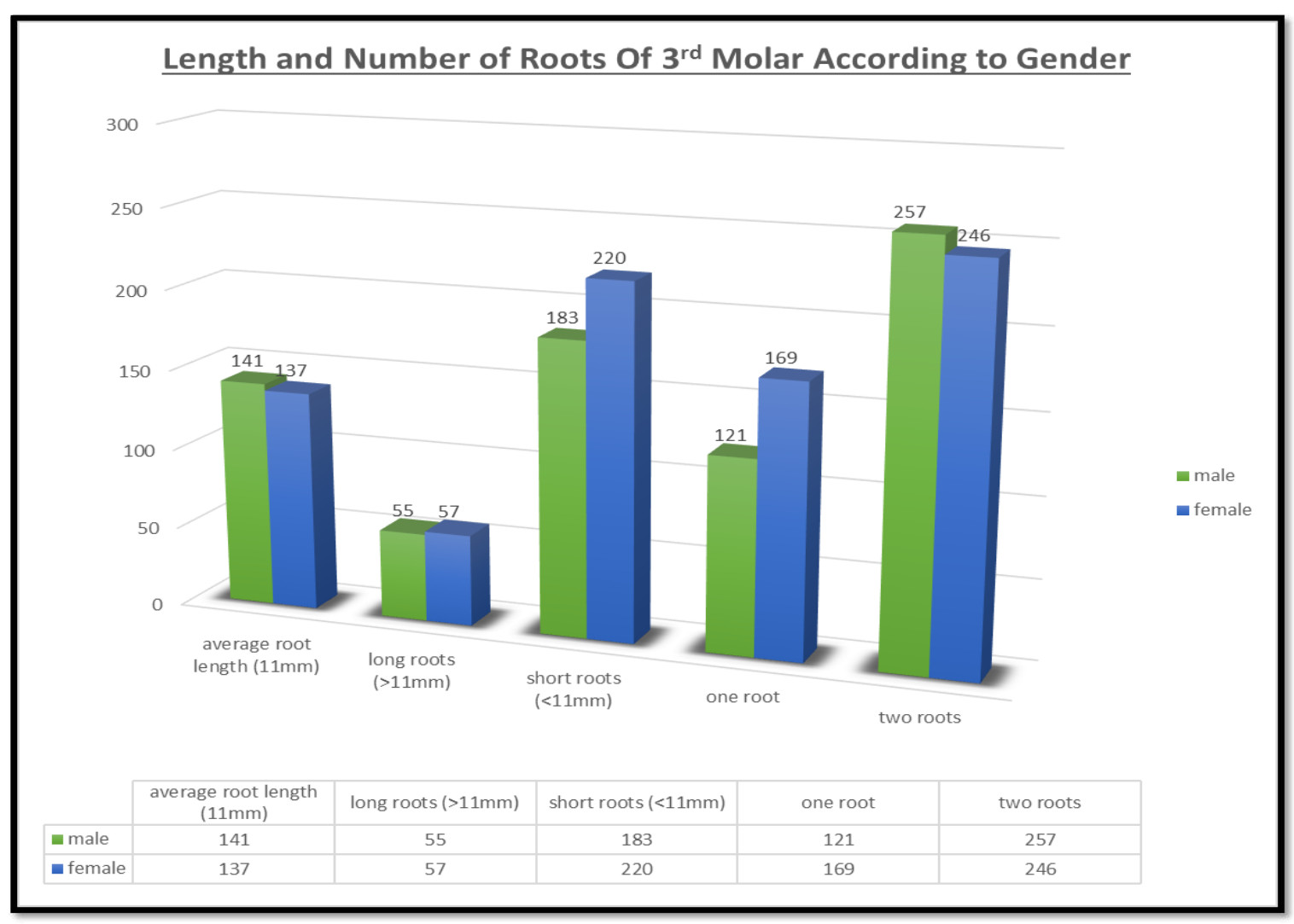

Graph 4. Length and Number of Roots of $3^{\text {rd }}$ Molar According to Gender 


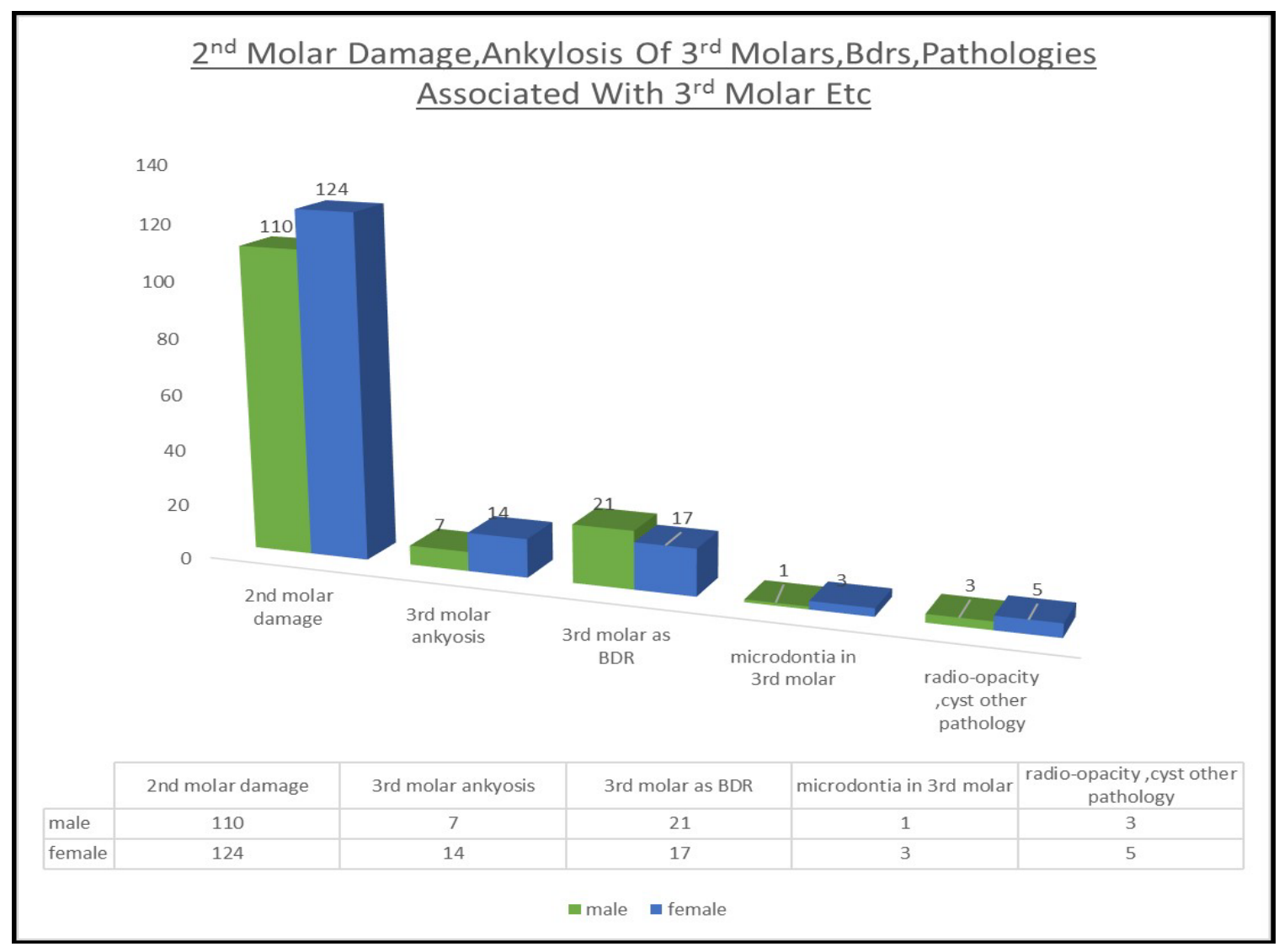

Graph 5. $2^{\text {nd }}$ Molar Damage, Ankylosis of $3^{\text {rd }}$ Molars, Bdrs, Pathologies Associated with $3^{\text {rd }}$ Molar Etc

Miloglo O et al. [20] reported in a Turkish population dilaceration in Maxillary and Mandibular third molar to be about $7.4 \%$ and $12.8 \%$ respectively, which is close to our finding of $11 \%$ and $20 \%$ in Maxillary and Mandibular third molars respectively.

Fused roots were the second most common in our present study, which is similar to Ira Franklin Ross et al. [21] who reported around $86 \%$ and $52.4 \%$ third molar fused roots in Maxilla and Mandible respectively.

Wang et al. [22] studied the relationship between mandibular third molar and IAC. He made used of panoramic radiograph plus CBCT to evaluate the distance. $22 \%$ of his cases reported distance between 1-3 $\mathrm{mm}$ between root apex and IAC. In our study in almost half of the cases the distance between third molar root apex and IAC were between 1 to $3 \mathrm{~mm}$. Variations in the results of previous studies than those of present study may be due to differing patient's ethnicities, density of mandibular bone and use of only 2D panoramic radiographs instead of advanced 3D imaging techniques.

Third molar that are partially erupted or are placed in a mesioangular or horizontal impaction are in risk of damage to second molar in form of development of caries in distal cervical region [23]. In present study $59 \%$ and $38 \%$ in Mandible and Maxilla respectively were seen to cause damage to adjacent second molar in form of caries or resorption.

Partially erupted Mesio-angular or Horizontally impacted third molars that contact the cement enamel junction of the second molar place this tooth at risk of developing caries in the distal cervical region. Sheikh et al. [24] study reported mandibular molars were more susceptible of causing damage to adjacent $2^{\text {nd }}$ molars than their Maxillary counterpart. Pankaj Yadav et al. [25] studied 1187 radiographs and concluded that 2 nd molar damage due to $3^{\text {rd }}$ molar angulation was more frequent in mandible (9.6\%) than maxilla (5.4\%).

Among pathologies associated with third molars, radiographic findings in our study concluded microdontia to the most common feature on panoramic radiograph which is also stated by Sharma et al. [26] who confirms that Microdontia is most commonly seen in maxillary lateral incisors and third molars.

\section{Conclusion}

The present study has given us some insight on radiographic variations observed in third molars of Patients attending Dow University OPD. Variations in our results from other studies can be accounted for different classification techniques used by other researchers such as use of 3D CBCT and etc. for more precise results, Cultural and ethnic diversity among different populations and different sample sizes and target population.

Implications of present study is females are accounting for more damage to adjacent second molars and probability of cyst and other pathologies and also have Inferior alveolar nerve at the level of Mandibular Molar roots, thus an OPG especially for young females can be essential in order to save adjacent tooth and other pathologies

Reports of present findings can help in early diagnosis in different types of impactions, which could further aid in early intervention in order to save the adjacent dentition.

Further studies are needed to compare variations in third molars in OPDS across the country by advanced radiographic techniques to get more detail reports on third molar variations. 


\section{References}

1. Quek SL, Tay CK, Tay KH, Toh SL and Lim KC (2003). Pattern of third molar impaction in a Singapore Chinese population: a retrospective radiographic survey. Int $J$ Oral Maxillofac Surg. 32: 548-552. [Crossref]

2. Alvira-González J, Figueiredo R, Valmaseda-Castellón E, Quesada-Gómez C and GayEscoda C (2017). Predictive factors of difficulty in lower third molar extraction: A prospective cohort study. Med Oral Patol Oral Cir Bucal, 22: e108. [Crossref]

3. Gupta S, Bhowate RR, Nigam N, Saxena S (2011) Evaluation of impacted mandibular third molars by panoramic radiography. ISRN Dent 2011: 406714. [Crossref]

4. Peterson LJ (1992) Rationale for removing impacted teeth: when to extract or not to extract. J Am Dent Assoc 123: 198-204. [Crossref]

5. Ahire BS, Bhoosreddy AR, Bhoosreddy S, Shinde MR, Pandharbale AA and Kunte VR (2016). Radiographic assessment of agenesis, impaction, and pararadicular radiolucencies in relation with third molar in Nashik City of Maharashtra. Journal of Dental and Allied Sciences 5: 3 .

6. Quek SL, Tay CK, Tay KH, Toh SL and Lim KC (2003). Pattern of third molar impaction in a Singapore Chinese population: a retrospective radiographic survey. Int $J$ Oral Maxillofac Surg 32: 548-552. [Crossref]

7. Sandhu S, Kaur T (2005) Radiographic evaluation of the status of third molars in the Asian-Indian students. J Oral Maxillofac Surg 63: 640-645. [Crossref]

8. Hattab FN, Rawashdeh MA, Fahmy MS (1995) Impaction status of third molars in Jordanian students. Oral Surg Oral Med Oral Pathol Oral Radiol Endod 79: 24-29. [Crossref]

9. Bayoumi AM, Baabdullah R, Bokhari AF and Nadershah M (2016). The Prevalence Rate of Third Molar Impaction among Jeddah Population. Int J Dent Oral Health 2.

10. Olasoji HO and Odusanya SA (2000). Comparative study of third molar impaction in rural and urban areas of southwestern nigeria. Odontostomatol Trop 23: 25-28. [Crossref]

11. Haidar Z and Shalhoub SY (1986). The incidence of impacted wisdom teeth in a Saudi community. Int J Oral Maxillofac Surg 15: 569-571. [Crossref]

12. Berger PL and Huntington SP (2002). Many globalizations: Cultural diversity in the contemporary world. Oxford University Press, USA.
13. Secic S, Prohic S, Komsic S and Vukovic A (2013). Incidence of impacted mandibular third molars in population of Bosnia and Herzegovina: a retrospective radiographic study. Journal of Health Sciences. 3.

14. Hashemipour MA, Tahmasbi-Arashlow M, Fahimi-Hanzaei F (2013) Incidence of impacted mandibular and maxillary third molars: a radiographic study in a Southeast Iran population. Med Oral Patol Oral Cir Bucal 18: e140-145. [Crossref]

15. Bataineh AB, Albashaireh ZS, Hazza'a AM (2002) The surgical removal of mandibular third molars: a study in decision making. Quintessence Int 33: 613-617. [Crossref]

16. Bayoumi AM, Baabdullah R, Bokhari AF and Nadershah M (2016). The Prevalence Rate of Third Molar Impaction among Jeddah Population. Int J Dent Oral Health 2.

17. Sidow SJ, West LA, Liewehr FR, Loushine RJ (2000) Root canal morphology of human maxillary and mandibular third molars. J Endod 26: 675-678. [Crossref]

18. Singh S, Pawar M1 (2015) Root canal morphology of South Asian Indian maxillary molar teeth. Eur J Dent 9: 133-144. [Crossref]

19. Townsend G, Bockmann M, Hughes T and Brook A (2012). Genetic, environmental and epigenetic influences on variation in human tooth number, size and shape Odontology 100: 1-9 [Crossref]

20. Miloglu O, Cakici F, Caglayan F, Yilmaz AB, Demirkaya F (2010) The prevalence of root dilacerations in a Turkish population. Med Oral Patol Oral Cir Bucal 15: e441444. [Crossref]

21. Ross IF, Evanchik PA (1981) Root fusion in molars: incidence and sex linkage. $J$ Periodontol 52: 663-667. [Crossref]

22. Wang Y, He D, Yang C, Wang B and Qian W (2012). An easy way to apply orthodontic extraction for impacted lower third molar compressing to the inferior alveolar nerve. $J$ Craniomaxillofac Surg. 40: 234-237. [Crossref]

23. Stanley HR, Alattar M, Collett WK, Stringfellow HR Jr, Spiegel EH (1988) Pathologica sequelae of "neglected" impacted third molars. J Oral Pathol 17: 113-117. [Crossref]

24. Sheikh MA, Riaz M and Shafiq S (2012). Incidence of distal caries in mandibular second molars due to impacted third molars-A clinical and radiographic study. Pakistan Oral \& Dental Journal 32.

25. Yadav P, Pruthi PJ, Nawal RR, Talwar S and Verma M (2016). Saving the 2nd Mola from the 3rd Is it Really the Guilt of the Tilt?. J Clin Diagn Res 10: ZC17-19. [Crossref]

26. Sharma A, Sharma S and Singh VP (2014). Concomitant hypodontia and unusual dental anomalies in families. Journal of Health Specialties 2: 82.

Copyright: (C2017 Jamil G. This is an open-access article distributed under the terms of the Creative Commons Attribution License, which permits unrestricted use, distribution, and reproduction in any medium, provided the original author and source are credited. 